\title{
Protecting the Right to Privacy IN CHINA
}

\section{Cao Jingchun*}

\begin{abstract}
This article suggests the Chinese government should establish systematic legal protection for personal privacy in China. First, a brief introduction to the history of the concept of privacy in China is given. Based on the definition of privacy in the Western world, the modern concept of privacy has been absorbed by Chinese scholars and defined according to Chinese norms. During this process, the subjects and objects of the right to privacy have been chosen and the distinctions between the right to privacy, the right of reputation and the right to know have been made clear. This article considers that it is most important to recognise the right to privacy as an independent right both in the Constitution and Civil Code. Depending on the impact of the breach of privacy, liability for civil or criminal punishment should attach. Besides these measures, a specific data protection law is also essential.
\end{abstract}

\section{INTRODUCTION}

The right to privacy has been recognised as one of the most fundamental human rights worldwide. "It has become one of the most important human rights of the modern age." ${ }^{1}$ Yet the development of legal protection of privacy in mainland China is at least 10 years behind that of Western countries.

Since the 1980s privacy has become a popular topic for academics and the media in China. Suddenly Chinese people have become aware of privacy, as shown by the increasing number of cases concerning a right to reputation since the 1990s. Before 2000, the focus was on general ideas of privacy, but in recent years the focus has shifted towards the protection of specific groups' rights to privacy - groups such as minors, students, patients, employees and consumers. The discourse about privacy and its legislation among legal scholars in China seems to have come to a head recently after 15 years' discussion. The inclusion of the right to privacy in the draft Civil Code was a landmark for the legal protection of privacy in China. ${ }^{2}$ The draft Code was submitted to senior legislators at the end

* Submitted as part of the LLM programme at Victoria University of Wellington.

1 Marc Rotenburg and Cedric Laurant Privacy and Human Rights: An International Survey of Privacy Laws and Developments (Privacy International, London, and Electronic Privacy Information Center, Washington DC, 2004).

2 China Legal Publicity and "China's Legislative Officials Solicit Advice for Civil Code" < http://www.legalinfo.gov.cn/> (last accessed 4 July 2004). 
of 2002 for preliminary reading. Presently, more than 200 laws or regulations in China mention privacy in some form. However, the general population of China is still not properly aware or accurately informed of the concept of privacy and the law does not sufficiently protect privacy rights.

The understanding of privacy changes with the passage of time and national traditions. China has developed its own concept of the right to privacy. During this process many issues have arisen about the elements of privacy or of the right to privacy. Many problems are still unaddressed, such as the conflict between the right to know and the right to privacy or the distinction between the right of reputation and the right to privacy. After discussing the historical background of the development of Chinese privacy, this article explains the existing Chinese legislation protecting this right. The author will suggest some ways for China to establish its own privacy protection system, using existing protections in other jurisdictions as models.

\section{TRADITIONAL CHINESE CONCEPTIONS OF PRIVACY}

China has one of the longest histories as a nation of any country in the world. In particular, the history of 2000 years of feudal society has had a great influence. In ancient China, people tended to pay more attention to nation and family than to individuals. In Chinese languages, the word "country" is written using two characters: the character for land and family. Country and family are connected closely and a person's responsibility was to serve both as long as he or she was a member of them. On the other hand, legislation in ancient China emphasised criminal and personal duties and ignored civil law and personal rights. Daily civil conduct was ruled by morals, rites, and the Confucian or feudal ethics code, which is called $\mathrm{Li}$ in Chinese. ${ }^{3}$

There is no agreement about whether "privacy" as such existed in ancient China. "Yinsi" is the Chinese word for privacy. However, it does not equate with the western concept of privacy. Yin and si are two words in Chinese: yin means "hide" and si means "private". It is this word which is most often used in legislation and is most familiar to Chinese lawyers. It is translated into English as "privacy", "personal secret" or "shameful secret". However it usually means something negative. In contrast, the related word "Yinsi" is closer to Western ideas of privacy. It includes "yinsi" but is defined as "a personal thing people do not wish to tell others or disclose in public". ${ }^{4}$

The two words are used confusingly though. It was initially common for Chinese to misunderstand privacy as relating to shameful secrets. It is unsurprising that an authoritative law dictionary defines both "cases of private matters (yinsi)" and the "cases of privacy (Yinsi)" as: ${ }^{5}$

3 " $L i "$ ", as defined by Confucius, is an order or system that regulates conduct especially between the king and his ministers, parents and children, friends, couples and the elder and the younger $<$ http://hk.geocities.com $>$ (last accessed 20 September 2004).

4 Modern Chinese Dictionary (2 ed, The Commercial Press, Beijing, 1978) 1363 and 1368.

5 Law Dictionary (3 ed, Shanghai Dictionary Publisher, Shanghai, 1989) 407 and 944. 
$[\mathrm{C}]$ ases of which the contents offend public decency, involve sexual affairs or other private matters and things. They are such as, in criminal crimes, rape, having sexual relations with minors; in indecent cases, indecent behaviour and insults towards a woman, sodomy, and prostitution; and unusual relationships concerning a third person intruding into the couple in cases of divorce, and so on.

Accordingly, most people consider privacy matters to be shameful to talk about publicly and do not want to disclose them. Therefore when their privacy is invaded they prefer to ignore the invasion if it is bearable; or sometimes choose to solve the problem themselves rather than going to court. ${ }^{6}$ In addition, the legal system for protecting privacy in China does not go far enough and is not a complete system. These are all barriers to the legal protection of privacy.

The author believes that privacy was protected, to some extent, in ancient China and an awareness of privacy may be found in the Warring States Period, ${ }^{7}$ though neither the word "privacy" (yinsi) nor the modern concept of privacy existed. One of the doctrines of Confucius is: Do not look, if it disagrees with $L i$; do not listen, if it disagrees with $L i$; do not talk, if it disagrees with $L i$. That doctrine operated to restrain people's speech and conduct to some degree, which included prohibiting invasion of a person's private life, especially disclosures of intimate relationships. The strict $L i$ rule governing conduct also severely limited basic autonomy, especially for women. Nevertheless, as it is today, private information was a staple of conversation with which to pass the time. Despite the awareness of shameful secrets in ancient China, strictly speaking there was no right to privacy.

Modern concepts of privacy and the right to privacy result from the development of the economy and democracy. Thus, the conditions for the existence of modern privacy began to form after the Chinese "reform and open" movement in late 1979, with the reform of the economic system. The market changed the face of China. In the Western world, some see globalisation and a growing economy as a threat to human rights because people are more and more focused on profit, but this is not the case in China. The developing economy brings people wealth, and globalisation brings people the latest knowledge, which makes people begin to be aware of their rights and encourages respect for others' rights and interests. Furthermore, people realise that distance between people is necessary and that they should respect others' own space - others' privacy. A busy and colourful life reduces people's interest and opportunity to talk about others' private matters, and people's views of the legal system also restrain their conduct. ${ }^{8}$ Finally, the market economy requires a free and stable environment to

6 Chen Yufan "Humble Opinions on Problems of the Citizens' Right to Privacy" (1994) (CAJ Full-text Chinese language Database) $<$ http://www.cnki.net $>$ (last accessed 4 July 2004).

7 The period of the Warring States (Zhanguo or Chan-Kuo) refers to the era of about 475 BC to 221 BC. It commenced at a time when the numerous petty city-state kingdoms had been consolidated into about seven major contenders and a few minor enclaves.

8 Wang Hong "Legal Thinking about the Right to Privacy" (1999) < http://www.cnki.net> (last accessed 4 July 2004). 
develop. ${ }^{9}$ For example, public confidence is essential for e-commerce and for the economy to grow. Internet based trading will continue only when customers have confidence that their privacy will be protected while they shop over the internet. Consequently, legal protection of privacy in China is critical.

\section{DEFINING "PRIVACY" AND THE RIGHT TO PRIVACY}

\section{A Western Countries}

As stated above, ${ }^{10}$ the modern concept of privacy is a Western creation. Since Warren and Brandeis identified the right to privacy as the individual's "right to be let alone" in $1890,{ }^{11}$ academics have discussed the definition of this right. They do not always agree. For example Judith Jarvis Thompson denied that the "right to be let alone" is the right to privacy because the scope of the former is either wider or narrower than the latter. ${ }^{12}$ Edward Bloustein wrote that privacy is an interest of human personality and to protect an individual's privacy is to protect the individual's personality, independence, dignity and integrity. ${ }^{13}$ According to Hyman Gross, "privacy is the condition of human life in which acquaintance with a person or with affairs of his life which are personal to him is limited," and "[a] legal right of privacy exists to the extent that such legal interest may be (not could be) accorded protection by legal procedures."14 In his definition, privacy comprises the following states of affairs: mental repose, physical solitude, physical exclusiveness and autonomy. ${ }^{15}$ Charles Fried sees privacy as related to respect, love, friendship and trust, and therefore sees protecting one's privacy as equal to protecting one's "very integrity as a person". ${ }^{16}$

In 1970, Alan Westin published Privacy and Freedom, which greatly influenced the concept of privacy. In his book, Westin described privacy as a "claim of individuals, groups, or institutions to determine for themselves when, how, and to what extent information about them is communicated to others," 17 and then further explained that: ${ }^{18}$

9 Yan Junxing and Wang Lizhong "Legal Protection and Compensation for Damage of the Citizens' Right to Privacy" (1996) <http://www.cnki.net> (last accessed 4 July 2004).

10 See Part I Introduction.

11 Samuel Warren and Louis Brandeis "The Right to Privacy" (1890) 4 Harv L Rev 193, 195.

12 Judith Jarvis Thomson "The Right to Privacy" in Raymond Wacks (ed) Privacy (Dartmouth, Aldershot, 1993) 3.

13 Edward Bloustein "Privacy as an Aspect of Human Dignity" (1964) 39 NYU L Rev 962, 971 (emphasis in original).

14 Hyman Gross "The Concept of Privacy" (1967) 42 NYU L Rev 34, 35-36.

15 Gross, above n 14, 37-38.

16 Charles Fried "Privacy" (1968) 77 Yale LJ 475, 477.

17 Alan Westin Privacy and Freedom (Bodley Head, London, 1970). 
[V]iewed in terms of the relation of the individual to social participation, privacy is the voluntary and temporary withdrawal of a person from the general society through physical or psychological means, either in a state of solitude or small-group intimacy, or, when among larger groups, in a condition of anonymity or reserve.

In contrast Tom Gerety defined privacy as "autonomy or control over the intimacies of personal identity" and insisted that a narrow definition of privacy is much better than a broad one. ${ }^{19}$ In line with Gerety, Jack Hirshleifer thought that the central domain of privacy "might be described as autonomy within society" but not as the idea of secrecy. ${ }^{20}$

However, in Ruth Gavison's view, a neutral concept of privacy is essential and should avoid describing privacy as "a claim, a psychological state or an area that should not be invaded" or even "a form of control". ${ }^{21}$ She mentioned that information known about an individual, attention paid to an individual and physical access to an individual are the features of privacy, or in other words, secrecy, anonymity and solitude. These three elements are independent and irreducible because invasion of privacy could be invasion of any of the three. The concept of privacy is constituted by these three elements and "is related to our concern over our accessibility to others". ${ }^{22}$ Wacks argued that, "at the centre of the concern about 'privacy' is the use (and especially the misuse) of personal information about an individual."23

It is therefore very difficult to define privacy. For the purposes of this article, the author has turned to Privacy and Human Rights 2004, a report published by Privacy International and Electronic Privacy Information Center. This report describes the development of the legal protection of privacy in 50 countries from 1997. It divides privacy into four "separate but related concepts". These were: ${ }^{24}$

[I]nformation privacy, which involves the establishment of rules governing the collection and handling of personal data such as credit information, and medical and government records. It is also known as "data protection";

Bodily privacy, which concerns the protection of people's physical selves against invasive procedures such as genetic tests, drug testing and cavity searches;

18 Westin, above n 17.

19 Tom Gerety "Redefining Privacy" (1977) 12 Harv CR-CL L Rev 234, 236.

20 Jack Hirshleifer "Privacy: Its Origin, Function and Future" (1980) 9 J Leg Stud 649, 649 (emphasis in original).

21 Ruth Gavison "Privacy and the Limits of Law" (1980) 89 Yale LJ 421, 426.

22 Gavison, above n 21, 423.

23 Raymond Wacks Personal Information: Privacy and the Law (Clarendon Press, Oxford, 1989) 20.

24 Rotenburg and Laurent, above n 1, "aspects of privacy". 
Privacy of communications, which covers the security and privacy of mail, telephones, e-mail and other forms of communication; and

Territorial privacy, which concerns the setting of limits on intrusion into the domestic and other environments such as the workplace or public space. This includes searches, video surveillance and ID checks.

These concepts summarise many countries' legal experience with privacy protection. This definition helps Chinese scholars to build up a picture of the elements of the concept of privacy.

\section{B China}

\section{General}

The Western discourse of privacy and the right to privacy has affected the discussion of privacy in China. From the 1990s, a few leading civil law scholars in China began to develop their own definitions of privacy and the right to privacy based on the discussion outside of China and the legal situation in China. First, Tong Rou, one of China's leading civil law scholars, wrote: "[t]he right to privacy, also called the right to private life, is a right of personality under which any interference by others with citizens' secrets and liberty of personal life is prohibited." 25 In the same year, another civil law academic, Professor Zhang, wrote: ${ }^{26}$

[T] he right to privacy is a legal right, by which citizens' residences, inner world, financial situations, social relations, sexual life, and past and current matters of purely personal nature they do not wish to divulge to the outside world are protected from any intrusion by others.

Zhu Lin also provided the following definition: "[p]rivacy is the personal matters people are not willing to divulge or to let others know; while the right to privacy is the right of freedom from publicity of personal secrets." 27 Following them, Wang Guan claimed that, "[t]he right to privacy is the right to withhold private affairs and secrets which only belong to the person and to prohibit the publicity of those without the person's consent."28

Later in 1994, another established civil law scholar, Wang Limin, analysed the existing definition of privacy and concluded: ${ }^{29}$

25 Tong Rou (ed) Chinese Civil Law (The Press of Laws, Beijing, 1990) 487.

26 Zhang Xinbao "On the Right to Privacy" (1990) <http://www.cnki.net> (last accessed 4 July 2004).

27 Zhu Lin "The Right to Privacy is a Personal Right that the Citizens of our Country shall Enjoy" $(1990)<$ http://www.cnki.net> (last accessed 4 July 2004).

28 Wang Guan "Statement of Rights of the Person" (1991) <http://www.cnki.net> (last accessed 4 July 2004).

29 Wang Limin (ed) Restatement of the Law of Rights of the Person (Jilin People's Press, Changchun, 1994$) 487$. 
[The] right to privacy is a right of personality, enjoyed by a natural person, under which he can dispose of all personal information, private activities and private areas which belong only to the person and have no relation to public interest.

A few years later a book edited by Professor Wang and Professor Yang explained the concept of privacy again. This concluded that the right to privacy is: ${ }^{30}$

[A] right enjoyed by natural person, under which the person is freedom from publicity and any interference by others with personal matters only related to the person and personal information such as affairs in the area of personal life.

They also stated the features of the right to privacy as being: ${ }^{31}$

- the subject of the right to privacy can only be a natural person;

- the objects of the right are private activities, and personal information; and

- the scope of protection of the right is limited by the public interest.

This definition has been adopted in the draft of the Civil Code 2002. ${ }^{32}$

As discussed above, the traditional Chinese understanding of privacy is quite different from that of Western countries, but it is not too difficult to find some common ground. This is possibly due to the fact that China already has the foundation established by Western countries in defining privacy. China had not has to start its research in privacy from zero because China can build on the Western experience.

\section{Subjects of the right to privacy}

(a) Legal persons' right to privacy

One argument in the West has been whether a legal person has a right to privacy. Westin held that groups and organisations can enjoy privacy because "[j]ust as individuals need privacy from social norms, so organisations need internal privacy to conduct their affairs without having to keep up a 'public face"'. 33

However, this does not seem to be the case in China. According to Chinese law, legal persons can be divided into three types: enterprises, official organs, and institutions and social organisations. Enterprises are independent economic organisations that pursue economic profit through commercial

30 Wang Limin and Yang Lixin (eds) The Law of the Rights of The Person (The Press of Laws, Beijing, 1997) 147.

31 Wang and Yang, above n 30, 146-148.

32 Above n 2.

33 Westin, above n 17 
activities. According to Yan Junxing and Wang Lizhong, enterprises have secrets (or confidential information), ${ }^{34}$ which are very important to the enterprise, and the disclosure of this information will be detrimental to the enterprise. However, these secrets are not called privacy of legal persons but instead are known as trade secrets. The first reason for this terminology is that privacy has no connection with public interest (although public interest may outweigh privacy) but the nature of trade secrets is directly related to public interest. The author agrees that the nature of legal persons' secrets and privacy are different. Secondly, the content of privacy and that of trade secrets is not the same. The former not only includes secrets but also other non-confidential information. Some private information is publicly known, such as people's physical impairments: (hare lip, blindness and so on) which are personal attributes but not secret. Nonetheless, if one considers privacy to be based on autonomy this information would be part of one's personal privacy and therefore should not abused but instead respected. In contrast, trade secrets consist of only confidential information. Such information is to be kept confidential from people outside the enterprise and sometimes even employees in the enterprise. Trade secrets are the property of those people who know the information and can use the information to achieve material benefits. If such information were divulged, it would cause loss to the enterprise. Consequently, the content and the extent of the secrecy of privacy and trade secrets are different. ${ }^{35}$

The majority of academic opinion in China argues that only a natural person has the right to privacy. Professors Liang Huixin and Liao Xinzhong explained that only a natural person could enjoy privacy because privacy originates from people's feelings. Secrets of legal persons or other organisations are trade secrets, which only relate to commercial reputation and economic profit and have no connection to personal feelings. ${ }^{36}$

Professors Wang and Yang also argue that the right to privacy is born out of the balance between individuals and society, and the right to privacy enables individuals to enjoy the peace of their inner world. The existence of the right to privacy is based on the emotions of natural persons. Legal persons or other such entities are not able to enjoy the right to privacy because they do not have feelings or emotions. The parallel right for legal persons is that relating to trade secrets, which is a property right. ${ }^{37}$

34 According to Chinese legal scholars, all information about organisations, especially enterprises, can be divided into two categories: public and confidential. There is no difference between trade secrets and other confidential information. See Yan and Wang, above $\mathrm{n} 9$.

35 Yan and Wang, above $\mathrm{n} 9$.

36 Liang Huixin and Liao Xinzhong "The Essence of Privacy and the Concept of the Right to Privacy" $(2003)<$ http://www.cnki.net> (last accessed 4 July 2004).

37 Wang and Yang, above n 30, 146-148. 
In this sense, the goal in protecting personal privacy is to prevent invasions of personal dignity. In contrast, protecting trade secrets involves protecting the economic benefits of the enterprise. ${ }^{38}$ One is intangible while the other is concrete. Therefore, privacy rights and trade secrets rights are too dissimilar to mix up.

Furthermore, Yan and Wang argued that applying to enterprises the concept of a legal person's right to privacy might have a negative effect. For instance, some enterprises would use "privacy" as an excuse to refuse to publicise the low quality of their products or service. This would harm consumers. ${ }^{39}$

Other kinds of legal person are official and institutional and social organisations, including social groups and mass organisations. Most of their activities are not-for-profit, and many scholars believe that these bodies' "public" nature should preclude them from involving the law of privacy to protect their secrets or confidential information. Yan and Wang thought that non-profit legal persons, and official organs especially should not enjoy privacy because they should be transparent to the public. By the same token, New Zealand's official information law emphasises the importance of official organs being open and accountable. ${ }^{40}$ If the privacy of such organisations were recognised, it would prevent the working of democracy and social probity. ${ }^{41}$ In Liang and Liao's opinion, the secrets of officials are a consequence of administration of public power, so it is impossible for the officials to have a right to privacy. ${ }^{42}$ The foundation of these two opinions is that the nature of privacy is "private" and the original source of privacy is a person's emotions or feelings. This therefore, means that legal persons can not enjoy privacy as such.

(b) An individual right or a public interest?

Despite a common conclusion, commentators disagree on the nature of privacy and the scope of the right to privacy. Many agree with Professors Wang and Yang that privacy is not a matter of public interest but is limited by the public interest. ${ }^{43}$ They claim that the objects of the right to privacy include private activities, personal information and private areas. Private activities are activities that are related to individuals and have nothing to do with public interest. These include one's daily life,

38 Yan and Wang, above n 9, 86-92.

39 Yan and Wang, above n 9, 86-92.

40 Official Information Act 1982.

41 Yan and Wang, above n 9, 86-92.

42 Liang and Liao, above $\mathrm{n} 36,42-45$. The author believes that it is very easy for people in China to find out the salary of individual officials, but this is not the case in New Zealand.

43 See for example Yan Li "The Design of the Legal System of Privacy" (2003) <http://www.cnki.net> (las accessed 4 July 2004); Qi Yong "Some Thoughts about the Right to Privacy" (2001) <http://www.cnki.net> (last accessed 4 July 2004); Li Yuanhua "Research on Fundamental Problems of the Right to Privacy" (2002) $<$ http://www.cnki.net> (last accessed 4 July 2004). 
social associations and sex life. Personal information includes individuals' height, weight, health condition, life experiences, and financial affairs. "Private area", also called "private space", is "bodily secrets" but can also include place of residence, and diary correspondence.

The right to privacy is not absolute and public interest can outweigh the right to privacy. When personal information is of great public interest, such information cannot be the object of the right to privacy. $^{44}$

However, Professors Liang and Liao doubted the above argument that the right to privacy is not related to public interest but at the same time is limited by it. They thought that even if privacy related to private affairs, it did not mean that privacy had nothing to with public interest. In practice, many personal matters or information belong to privacy and are at the same time related to the public interest. An example would be, a person made a donation but did not want his or her name to be public. ${ }^{45}$ In this example, the donation is a private affair but at the same time is connected with public interest because it is a charity that is set up to benefit society. Furthermore, people belong to society and cannot exist without society. As Wacks said, "at the heart of the concern to protect 'privacy' lies a conception of the individual and his or her relationship with society."46

(c) Privacy of the deceased

If the goal of protection of personal privacy is to protect dignity and feelings, dead people have no feelings about the disclosure of personal information, so it is not necessary to extend the protection to cover them. Often claims for privacy of deceased people are not only related to the deceased themselves but also to other living people such as their relatives and friends. In this case, living people involved can legally protect their privacy and at the same time protect the privacy of the deceased. On most occasions, revelation of personal information only relating to the deceased would change people's view of the deceased, and have a negative impact on the reputation of the deceased. Therefore, according to Chinese law, it is a matter of defamation rather than a breach of privacy. Also, the civil right to privacy ends when a citizen dies. So deceased people do not enjoy the right to privacy.

Some people think that under existing Chinese law the deceased enjoy an intellectual right and also the right to reputation, ${ }^{47}$ and thus the law should not prohibit the deceased from enjoying the right to privacy as well. The 2001 Judicial Interpretation of Compensation for Emotional Damage

44 Wang and Yang, above n 30, 146-148. In the author's opinion, "public interest" as used in everyday language in Chinese is much broader in scope than the concept is in Western countries, but in legal use it is equivalent.

45 Liang and Liao, above n 36, 42-45.

46 Wacks, above n $23,7$.

47 This is not the case in New Zealand. See for example John Burrows "Defamation" in Stephen Todd (ed) The Law of Torts in New Zealand (4 ed, Brookers, Wellington, 2005) ch 17. 
provides for the legal protection of dead people's privacy, ${ }^{48}$ as does the draft Civil Code. ${ }^{49}$ However, the author thinks that while the deceased have an intellectual right, the right to reputation is incomplete. Article 3 of the Judicial Interpretation clearly states that the relatives can litigate after a natural person's death if their feelings have been injured by the disclosure of the deceased's personal information. ${ }^{50}$ In other words, the law does not provide that publicising the deceased's personal information is illegal, as long as this disclosure does not injure the feelings of the deceased's relatives. Likewise, in New Zealand, if surviving family members have their information disclosed because it is mixed with personal information about the deceased, they can claim for breach of their own right to privacy.

\section{The right to privacy, the right to reputation and the right to know}

There are few Chinese cases which directly discuss a right to privacy. Instead, other terminology is used, such as a right to one's portrait, or, most commonly, a right to reputation. Typical cases of invasion of privacy are Two Art Models $v$ The Organisers of the Exhibition and The Rock ' $n$ ' Roll Star Cui Jian $v$ The Writer Zhao Jianwei and his Publisher accompanied by two Judicial Interpretations in 1988 and 1993 about adjudicating cases relating to the right to reputation. ${ }^{51}$ In the case of Two Art Models $v$ The Organisers of the Exhibition some teachers from the China Central Art Institution held an exhibition of life drawing without the consent of the models. Later, the models sued the organisers for invasion of their right of portrait. However, some scholars thought that it was actually an invasion of privacy dealt with under the more familiar name of invasion of the right of portrait. This is because what was disclosed was the plaintiffs' professional secrets and parts of their bodies, and the disclosure subjected the models to pressure from society and their families, which caused great emotional damage. ${ }^{52}$

48 Interpretation to Several Questions on Emotional Damage Compensation Liability for Civil Infringement of Rights 2001 (Interpretation 2001), art 3: After the death of natural persons, their close relatives can sue for compensatory damages on the following grounds and the Court should handle the case according to the law: (2) illegal disclosure or use of the deceased's private information or invasion of privacy by other means which violate the public interest or social morals. (Translated by the author) $<$ http://www.chinacourt.org $>$ (last accessed 4 July 2004)

49 Yuanhua, above n 42.

50 Above $\mathrm{n} 47$.

51 Confirmation and Answer to the Question about Jurisdiction and whether Newspaper or Magazine Office should be Defendant in Reputation Invasion Cases 1988 (invalidation) <http://www.chinacourt.org $>$ (last accessed 4 July 2004); Reply to Several Questions on Adjudicating the Cases of the Rights of Reputation $1993<$ http://www.chinacourt.org $>$ (last accessed 4 July 2004).

52 Chen Yumei "The Legal Protection of the Right to Privacy and its Perfection" $(2002)<$ http://www.cnki.net> (last accessed 4 July 2004). 
Some cases have resulted in the imprisonment of journalists. As in the West, privacy debates in China involve the question of the proper balance to be struck between the right to privacy and the right to know, and the appropriate ethical norms that should govern the conduct of the journalists and the freedom of the press. ${ }^{53}$ Following the above two Judicial Interpretations in 1988 and 1993 another two Judicial Interpretations were decided by the Supreme People's Court in 1998 and 2001, ${ }^{54}$ and further questions were raised regarding the scope of the right to privacy and where the line should be drawn between the right to reputation and the right to privacy. These mirror some issues in privacy debates in other countries.

(a) Neutrality of privacy law

In China, not all privacy is seen as worth protecting by law. Where what is at stake is "yinsi" (a shameful secret) the law will not always protect it. According to Liang Huixing and Liao Xinzhong, privacy is a personal natural right and objective fact. ${ }^{55}$ Thus privacy can be categorised as legal (or lawful) privacy and illegal (or unlawful) privacy. Later in their article, unlawful privacy is divided further. Their main point is that the privacy of information about facts that constitute serious violations of public order or good morals, such as bigamy or extramarital sexual conduct, should not be protected by law. In addition, Liang and Liao argue that their opinion is supported by the function of Chinese law because one of the important roles of Chinese law is to address important social public morals. ${ }^{56}$ This point is also reflected in the General Principles of the Civil Law, which states that "[c]ivil activities shall have respect for social ethics and shall not harm the public interest ... ." 57 In other words, for Liang and Liao, privacy protection is intricately bound up with public interest - that is, acceptable standards of conduct.

Although the categories of privacy discussed by Liang and Liao are clear and understandable, using morality as a legal standard is not necessarily inappropriate. Legislation should be neutral and rational. On the other hand, legislation sometimes may set a standard more liberal than the expectation of the majority of citizens. If public views or public morals were used as a standard to evaluate the legislation, advancement might not have been possible in legislation for interracial marriage or recognition of homosexual relations.

53 Zhu Guobin "The Right to Privacy: An Emerging Right in Chinese Law" (1997) 18 Statute L R $208,211$.

54 Interpretation to Several Questions on Adjudicating the Cases of the Rights of Reputation 1998 $<$ http://www.chinacourt.org $>$ (last accessed 4 July 2004).

55 Liang and Liao, above n 36, 42-45.

56 Liang and Liao, above n 36, 42-45.

57 General Principles of the Civil Law of the People's Republic of China $1986<\mathrm{http}$ //en.chinacourt.org> (last accessed 4 July 2004), art 7. The Judicial Interpretation by the Supreme People's Court of the People's Republic of China's Opinion on Several Questions Concerning the Implementation of the General Principles of Civil Law of the People's Republic of China, $1988<\mathrm{http}$ ://www.chinacourt.org > (last accessed 4 July 2004). 
A case also proved that the opinion of Liang and Liao has not been adopted by the judiciary. Li Jin and Wang Hua were married. At the end of 1999, Li Jin met another woman, Liu, and corresponded with her for some time. Later, Wang Hua discovered 24 love letters her husband and Liu had written to each other. She was so angry that she often abused the two people in public and pasted copies of their letters everywhere. Li Jin pursued an action in court. The court held that Wang Hua's activities breached Li Jin's right to reputation and demanded that the infringement be stopped. ${ }^{58}$ But Liang and Liao argued in contrast that Li Jin breached the duty of loyalty between couples as provided in the Marriage Law, ${ }^{59}$ and that was "unlawful privacy" so it should not be protected. ${ }^{60}$

In this case, both the wife and the husband were victims. Wang Hua's activities broke the law and constituted a breach of the tort of reputation. Wang Hua could have enforced her own legal right through legal procedure. The fact that she was hurt by her husband first does not mean that she can hurt her husband by any means. What Wang Hua revealed was Li Jin's personal information and also Liu's personal information. Wang Hua could have chosen to achieve her goal by lawful means, but she chose to instead use unlawful means. Society should not condone her choice, so the author supports the judgment of the court. On similar facts an English court came to the same conclusion. ${ }^{61}$

(b) The right to privacy and the right to reputation

Another important issue raised in Wang Hua's case was the distinction between the right to privacy and the right to reputation. Since 1988, privacy litigation has been generally subsumed in reputation cases. Scholars accept it is more practical to protect privacy as part of the right of reputation, but they also point out that this protection is insufficient because of the differences between the two rights. A case highlights this point. A story was fabricated that Wang had left a wounded accident victim without offering assistance. Actually Wang had been hurt while saving others and he was sterile as a result of his injuries. The truth was published later. No doubt the news redeemed Wang's reputation but, ironically, invaded his privacy at the same time. ${ }^{62}$

The protection of the right to privacy is narrowed by the existing system including it in the right to reputation. The right to privacy and the right to reputation are connected to each other in many cases because the publication of private information will not only result in emotional damage but it may also

58 Liang and Liao, above n 36.

59 Marriage Law of the People's Republic of China 2001, art 4: "The couple shall be loyal to each other ..." < http://www.chinacourt.org> (last accessed 31 July 2004).

60 Liang and Liao, above n 36.

61 Argyll v Argyll [1967] 1 Ch 302. The Duke disclosed the Duchess's personal information after they divorced. The Court held that he had breached his wife's confidence.

62 Yan Yilun "On Concepts and Characteristics of the Right of Privacy" (2000) <http://www.cnki.net> (last accessed 4 July 2004) 
have an impact on reputation. However, although the right to privacy as an independent civil right is parallel to the right to reputation it has at least five aspects that are different from the latter right.

First, the subjects of the rights are different. Both natural persons and legal persons can be the subjects of the right to reputation. The right to reputation is vital to legal persons, especially to enterprises, because their reputation is directly related to their economic profits. Deceased people also enjoy the right to reputation in China. As discussed above, subjects of the right to privacy can only be natural persons, which excludes dead people. ${ }^{63}$

Secondly, the objects (or the nature) of the rights are not the same. Reputation is a social appraisal, which is not a self-evaluation or feeling nor an assessment of others by specific people but a general assessment or recognition of the citizens' or legal persons' strengths, weakness, and value by some social groups. Reputation is public and open. However privacy focuses on the control of personal information including an ability to prevent disclosure: it "demands that the personal information shall not be illegally obtained and disclosed, that private life not be unlawfully invaded and that there be no unlawful interference with any decisions concerning private matters". ${ }^{64}$

Thirdly, the contents of the torts of the breach of the respective rights are different. An invasion of the right to reputation by means of insults, or defamation of others, or fabricating facts to publicly vilify others, causes a negative impact on the person concerned. Fabrication is the character of the action of breach of the right to reputation and negative impact is the consequence of the action. In contrast with the tort of reputation, elements of the invasion of privacy not only include disclosure to a third party or negative impact of the disclosure but also an intrusion into solitude. It is a right "to be let alone". What is disclosed in the tort of privacy is true information, but in defamation cases the information is false.

Fourthly, the disposal of the two rights is not the same. In China the content of the right to reputation is the social appraisal of the subject and the subject cannot unilaterally abandon or dispose of an action. The right to privacy is a private right belonging to the subject completely, so the subject can choose how to deal with it, such as giving up some or all of his or her right to privacy.

Finally, the liability and damages compensation for the two rights are different. According to the General Principles of the Civil Law: ${ }^{65}$

If a citizen's right of personal name, portrait, reputation or honour is infringed upon, he shall have the right

to demand that the infringement be stopped, his reputation be rehabilitated, the ill effects be eliminated and an apology be made; he may also demand compensation for losses.

63 See part III B 2 Subjects of the right to privacy.

64 Zhu, above n 52, 211.

65 General Principles of the Civil Law of the People's Republic of China, above n 56, art 120. 
In contrast, under the tort of privacy, once personal information has been divulged, the ill effects cannot disappear, at least in a short period of time. Protecting the right to privacy ex ante is especially critical; prevention is more important than compensation. Thus it is essential to set up the right to privacy as an independent right and to specially protect such a right.

In the story above, Wang has no legal redress if the right to privacy is only protected under an action for breach of the right to reputation. It is essential to distinguish these two rights in order to protect the right to privacy.

(c) Public figures

In China, as in the West, the right to privacy is limited by the concept of the right to know. The limitation appears most often in instances involving public figures.

The right to know means that the public have a right to know information of legitimate public concern, and the law should recognise and safeguard to the maximum extent the public's right to be informed and seek information, especially in relation to the disclosure of information about government affairs. Fen Juping argues that all social information can be divided into two categories: legally protected information (including national secrets, legal persons' trade secrets and personal information) and information not protected by law. A citizen's right to know is restricted to the latter type of information. According to Fen therefore, there is no conflict between the right to privacy and the right to know, because the material to which these two rights relate is different. ${ }^{66}$

Yin Xiaomin also discussed in detail the relationship between the right to know and the right to privacy. The definition given above for the right to know is in broad terms. More strictly, it is only the right to know information about state officials or governments.

In China, as elsewhere, even when citizens go to great lengths to protect their own personal information such as their private photographs, telephone numbers, and addresses, they also have a strong curiosity to know all kinds of private information about public figures such as movie stars or famous scholars. Besides the incentive of commercial profits, the invasion of public figures' privacy by the press is increasingly demanded to satisfy the public curiosity. Consequently, the conflict between the protection of public figures' privacy and freedom of speech becomes very apparent.

This topic has been debated for more than 10 years in China, and the judgment in a case at the end of 2002 was a milestone in this area. A famous Chinese football player, Fan Zhiyi, sued Shanghai's Eastern Sports Daily for invasion of reputation. ${ }^{67}$ The court overruled Fan's claim because he was a public figure and therefore should endure any damage caused by the media as long as they conduct

66 Fen Juping "Approaching the Right to Privacy" (1998)<http://www.cnki.net> (last accessed 4 July 2004).

67 Some think that although this case has been treated as an invasion of reputation, actually it is a case about balancing the right to privacy with the right to know. The defendant reported falsely that the plaintiff had gambled on the result of the match. 
their work in a reasonable manner. ${ }^{68}$ This case recognised that public figures' privacy is different from that of ordinary citizens and sometimes public figures have to sacrifice part of their privacy in the public interest. Government officials are in the same situation. When the public seek information about government officials in order to find out about the running or administration of government, officials cannot refuse to provide the information on the ground that disclosure would breach their right to privacy. ${ }^{69}$

In conclusion, debate over the scope of privacy rights is, in many respects, not particularly different in China from in the West. However in practice privacy cases still have to be handled as "reputation" cases since reputation is a more familiar term for judges. This may change if effective privacy legislation is introduced in China, for example as part of the Civil Code.

\section{DEVELOPING CONSTITUTIONAL PROTECTION OF PRIVACY}

Many individual laws in China recognise privacy protection in some form. ${ }^{70}$ However, there is no overarching privacy legislation in China. This makes privacy protection weak in many instances.

The constitution provides some limited protection, which can serve as a foundation for further developments. Articles 38 and 39 of the Constitution provide that personal dignity and the homes of citizens are inviolable and article 40 gives legal protection to the freedom and privacy ( $\mathrm{mimi}$ ) of correspondence of citizens. ${ }^{71}$ Almost all Chinese academics argue that these three articles are the constitutional basis for the legal protection of a right to privacy. However without other supporting legislation, or a clear conception of what privacy is, the Constitution has not been used to protect privacy in the way it might be.

Privacy is not an independent civil right in civil law and therefore a court does not recognise an invasion of privacy as constituting an independent claim in litigation despite protection through other laws and regulations. ${ }^{72}$ Additionally, as discussed above, confusion between invasion of privacy and reputation prevents the development of the legal protection of privacy, because reputation has been used to compensate for the lack of direct privacy protection in China. To fully develop privacy

68 Chunchen and Xiuying, above $\mathrm{n} 83$.

69 Yan Deng "Protection of Privacy Rights in the Judicial Explanation of Spiritual Harm Compensation" (2003) $<$ http://www.cnki.net> (last accessed 4 July 2004).

70 Article 40 of the Constitution states that legal protection of the freedom and privacy ( $m i m i)$ of correspondence of citizens. The General Principles of Civil Law (GPCL) and the judicial interpretation of the GPCL declares the personal right to portrait and the right of reputation and law protects the personality of every citizen in which include protection of some part of people's privacy. Also you can find a form of practical protection of privacy in criminal law, procedure law and other legislation.

71 Sometimes, people also translate the Chinese word "mimi" as "privacy", but it usually means "secret".

72 Yang Junlin "Legal Protection of the Right to Privacy" (2000) <http://www.cnki.net> (last accessed 4 July 2004). 
protection, the right in the constitution must clarify some of these confusions and take a more principled and systematic approach to privacy protection. This does not preclude a comprehensive law such as a data protection code. On the contrary, a data protection law is a vital adjunct to other forms of protection.

\section{A Constitution}

Zhao Yong and Luo Yuelin tried to explained why the right to privacy should be a constitutional right and how the Constitution should protect this right. Indeed, for economic reasons as well as for privacy protection for its own sake, such a law is essential. However, constitutional protection will send important signals about the significance of privacy in a modern state. ${ }^{73}$

China signed the International Covenant on Civil and Political Rights in 1998 and ratified the International Covenant on Economic Social and Cultural Rights in $2001 .{ }^{74}$ Provisions similar to article 12 of the Declaration that protect citizens' privacy, family, home and correspondence can be found in article 17 of the International Covenant on Economic Social and Cultural Rights. China, as a signatory to these two international covenants, should not only respect the rights protected by these covenants, but also make sure that in practice Chinese laws protect the right to privacy.

For example, the international protection of the right to privacy requires the Constitution to include a right to privacy. The Constitution is a bridge connecting domestic and international law. As the fundamental law of the country the Constitution has supreme law status over other domestic laws. Therefore, declaring the right to privacy as being a constitutional right is clearly very important. ${ }^{75}$ Ensuring the right to privacy in the constitution will promote and encourage its protection by increasing Chinese citizens' recognition of the right's importance. People will learn to respect the right to privacy and, consequently, the development of the legal protection of privacy will be accelerated.

Constitutional protection of privacy rights can be seen as consistent with their civil law protection. Therefore, the Chinese Constitution should explicitly guarantee the right to privacy in article 38 as: "[c]itizens of the People's Republic of China enjoy their privacy right in the personal life and family life". ${ }^{76}$ In the author's view China can learn much from the privacy protections established in France and Germany's civil law systems. Some argue that countries with civil law systems provide protection of the right to privacy superior to that provided in common law systems

73 Zhao Yong and Luo Yuelin "Constitutional Protection of the Right to Privacy" (2002) < http://www.cnki.net> (last accessed 4 July 2004).

74 International Covenant on Civil and Political Rights (16 December 1966) 999 UNTS 171; International Covenant on Economic, Social and Cultural Rights (16 December 1966) 993 UNTS 3.

75 Zhao and Luo, above n 72.

76 Guo Zhixiang and Zhang Xiaobing "The Protection of the Right to Privacy in Legal Society" $<$ http://www.cnki.net> (last accessed 4 July 2004). 
(or Anglo-American law systems) because they explicitly protect citizens' private life with powerful prevention regulations in their civil law rather than the courts having to follow precedents in the common law system. ${ }^{77}$

Besides the rationales discussed by Zhao and Luo, the author thinks that there is another important reason for including the right to privacy in the Chinese Constitution. In China, the Constitution is "positive" rather than "negative". Citizens' fundamental rights are granted by the Constitution and the constitution emphasises their importance. Rights such as freedom of speech, freedom of religious belief and the right to know are included in the Constitution. ${ }^{78}$ As China has already acknowledged the right to privacy as a fundamental human right, along with freedom of speech and other human rights, then in accordance with this tradition, the right to privacy should be explicitly provided in the Constitution. Although legislators cannot amend the Constitution overnight, they have at least showed their willingness to do so. The revised Constitution states that the law in China protects all human rights. $^{79}$

\section{B Civil Code (including tort)}

After the right to privacy has been recognised as a constitutional right, it is necessary to define the scope of the right in the new Civil Code. Based on the majority of academic opinions on the definition of privacy, the new draft Civil Code defines the scope of privacy as including personal information, private activities and private area, and states that natural persons enjoy the right to privacy and that invasion of privacy by any means is prohibited. ${ }^{80}$ Compared with the concept of privacy in other countries, the author believes that little change will be made to this definition in China in the near future. As discussed previously, an authoritative definition of privacy has already been accepted by the majority of academics and has been written in the draft Civil Code, so it is unlikely that any amendment will be made.

Complementing Constitutional protection against government invasion of personal privacy, the law of tort allows citizens to protect their privacy from invasion: victims can take legal action to protect their right to privacy and seek compensation. The United States, New Zealand, Germany, and France have all adopted this model. In contrast, in the model of indirect protection of privacy, the right to privacy is not recognised as an independent personal right. When one's privacy has been invaded, the person can litigate this breach, but such action must be taken in the name of other causes of action

77 Zhang Xuke "Emerging Legislation on the Protection of the Right to Privacy" <http://www.cnki.net> (last accessed 4 July 2004).

78 Constitution of the People's Republic of China 1982, arts 35, 36 and 40.

79 Constitution of the People's Republic of China 1982, art 33.

80 "Civil and Commercial Law" < http://www.civillaw.com.cn> (last accessed 4 July 2004). 
or torts, such as breach of confidence or invasion of reputation. Typical examples of countries with indirect protection are the United Kingdom and Australia.

Since the right to privacy will become an independent right in China under the Civil Code, the next step is to explore the scope of the tort of privacy, including both the elements of the tort and civil liability for invasion of privacy. It has been said that most Chinese civil law scholars believe that there are four elements of the tort of privacy: action of invasion, fact of damage, causality between the action and the damage, and subjective fault. ${ }^{81}$ However, the second and the fourth elements are controversial. $^{82}$

There are arguments to say that illegal or unfair collection and disclosure is always a breach of privacy. However, tort cases take a different view, ${ }^{83}$ as does data protection legislation. ${ }^{84}$ In addition, it is unclear whether intention should be an element of the tort of privacy. As long as the conduct has invaded another's privacy, whether the action is intentional or by accident, it is still an invasion of privacy. Although it is not certain that intention or damage should necessarily be elements of the tort, they should be considered when determining civil liability. The other two elements, the action of invasion and sufficient causality, are especially critical when considering degree of compensation. Finally, as we have seen, civil liability under the tort of privacy in China will be, to some extent, similar to breach of reputation, ${ }^{85}$ and therefore compensation for breach of privacy can rely on the Judicial Interpretation regarding emotional damage. ${ }^{86}$

There is also an alternative form of civil law protection. Japan uses a "general protection model". ${ }^{87}$ Under a general protection model, civil law or other related laws and precedents summarise the protection of personal rights or personal dignity, but do not list the specific rights. However, citizens' privacy has been protected in practice and has been the subject of provisions in related laws and regulations separately. ${ }^{88}$ Since World War II, Article 709 of the Japanese Civil Code has been a very flexible provision that protects rights of citizens and establishes "personal dignity and substantial equality of both genders" as the highest principle in the interpretation of civil laws, in

81 Qi Yong, above n 43.

82 Huang Ying "Bi-directional Conversely Thinking about Tort and Right to Privacy" $(2002)<$ http://www.cnki.net> (last accessed 4 July 2004).

83 See for example Hosking $v$ Runting [2005] 1 NZLR 1 (CA).

84 See for example Privacy Act 1993, ss 66

85 See part III B 3 The right to privacy, the right of reputation and the right to know.

86 Interpretation 2001, above $\mathrm{n} 47$.

87 Zeng Peifang, "On Privacy Right and the Protection of Civil Laws" (2002) < http://www.cnki.net> (last accessed 4 July 2004).

88 Zeng, above n 85, 87-89. 
which personal dignity is thought to encompass the right to privacy. ${ }^{89}$ This model is actually very close to the existing situation in China. Although it may work well in Japan, the author views it as insufficient for China. In the late 1980s Japan also adopted data protection legislation to strengthen privacy protection. In common with most Chinese comment the author therefore favours the implementation of a specific provision protecting privacy in the Civil Code. The parameters of that provision, however, will need to be worked out over time.

\section{CONCLUSION}

Privacy protection and the relevant legislation and judicial practice is a challenge for Chinese citizens, judicial officials and the government. Additional privacy protection is required. Two suggestions made here are development of the Constitutional right of privacy, and proper implementation of the provision in the Civil Code. Another, not discussed here, would be development and implementation of data protection legislation. The benefit of the latter would be not only increased information privacy protection but also economic benefit for China. Currently in China, the potential in the system is much more advanced than the actual practice. The judicial system lacks independence from government and judicial personnel, especially in inland China, and can be corrupt. In less developed districts the weakness of lawyers also contributes to limit the legal support available to many Chinese citizens.

Although China faces so many practical problems, the author believes that China has the ability to apply an effective model to protect the right to privacy. In order to achieve that goal, the Constitution needs to be amended and the new Civil Code needs to be enforced as soon as possible. In addition, to be in line with the above suggested legislation, other law departments must change or add provisions about privacy. In case of serious invasions of privacy or resulting in serious consequences, the invader should bear criminal liability.

Chinese people, like others, need privacy. It is a concept that, though less developed, is not alien to Chinese society and culture. From shameful secrets to personal information, from arbitrary invasion of privacy to legal protection of privacy, the Chinese people and government have already done a lot in this area. Based on the future Civil Code, the author believes an independent tort of privacy will replace today's situation where there is no distinction between the torts of privacy and reputation. At the same time, specific data laws and official agents, a comprehensive model in privacy protection, will be set up. During the process, foreign experience will be a useful reference. Privacy protection is not a task for China alone, but for the entire world.

89 Zeng, above n 85, 87-89. 